\title{
Timing of Australian flight attendant food and beverage while crewing: a preliminary investigation
}

\author{
Sally Lee PERRIN ${ }^{1 *}$, Jillian DORRIAN ${ }^{1}$, Charlotte GUPTA ${ }^{1}$, Stephanie CENTOFANTI ${ }^{1}$, \\ Alison COATES ${ }^{1}$, Lyla MARX ${ }^{1}$, Karyn BEYNE ${ }^{1}$ and Siobhan BANKS ${ }^{1}$ \\ ${ }^{1}$ Behaviour-Brain-Body Research Centre School of Psychology, Social Work and Social Policy, \\ University of South Australia, Australia
}

Received March 26, 2018 and accepted September 26, 2018

Published online in J-STAGE October 19, 2018

\begin{abstract}
Flight attendants experience circadian misalignment and disrupted sleep and eating patterns. This survey study examined working time, sleep, and eating frequency in a sample $(n=21,4$ males, 17 females) of Australian flight attendants (mean age $=41.8 \mathrm{yr}, \mathrm{SD}=12.0 \mathrm{yr}$, mean $B M I=23.8 \mathrm{~kg} / \mathrm{m}^{2}, \mathrm{SD}=4.1 \mathrm{~kg} / \mathrm{m}^{2}$ ). Respondents indicated frequencies of snack, meal, and caffeine consumption during their last shift. Reported sleep duration on workdays (mean=4.6 h, SD=1.9 h) was significantly lower than on days off $(M=7.2 \mathrm{~h}, \mathrm{SD}=1.2 \mathrm{~h}, p<0.001)$, and significantly lower than perceived sleep need $(\mathrm{M}=8.1 \mathrm{~h}, \mathrm{SD}=0.8 \mathrm{~h}, p<0.001)$. Food intake was distributed throughout shifts and across the $24 \mathrm{~h}$ period, with eating patterns incongruent with biological eating periods. Time available, food available, and work breaks were the most endorsed reasons for food consumption. Caffeine use and reports of gastrointestinal disturbance were common. Working time disrupts sleep and temporal eating patterns in flight attendants and further research into nutritional and dietaryrelated countermeasures may be beneficial to improving worker health and reducing circadian disruption.
\end{abstract}

Key words: Flight attendants, Shift work, Sleep, Meal timing, Eating patterns, Work environments, Health, Circadian disruption

Engagement in non-standard working time, commonly referred to as shiftwork, is associated with disruption to circadian rhythms, negatively impacting sleep and performance and overall health and well-being ${ }^{1-3)}$. A unique group of shiftworkers are flight attendants, whose role encompasses general administrative duties, providing passenger comfort during in-flight service and maintenance of passenger safety and order ${ }^{4,5)}$. The working time of flight attendants includes lengthy and irregular hours of work, in addition to restrictive working spaces and transmeridian travel $^{4,5)}$. Associated with such a complex work schedule,

\footnotetext{
*To whom correspondence should be addressed

E-mail: sally.perrin@mymail.unisa.edu.au
}

(C)2019 National Institute of Occupational Safety and Health the circadian systems of flight attendants are chronically disrupted, creating a misalignment between the internal circadian clock, and environmental time-cues such as light and eating behaviour ${ }^{3,6,7)}$. The circadian clock located in the brain is responsible for various near $24 \mathrm{~h}$ biological rhythms important for human health ${ }^{3,6,7)}$. The circadian or 'master clock', regulates peripheral clocks including cells, tissues and organs that support metabolic health ${ }^{6,7)}$. Laboratory studies show that circadian misalignment of sleep and food timing results in considerable metabolic disturbance ${ }^{8,9)}$. Shiftwork in general is associated with changes in eating behaviours and, in turn, the functioning of metabolic systems $\mathrm{s}^{2,3,7-10)}$.

The breadth and idiosyncratic nature of health and safety issues arising from such misalignment are evident 
in many shiftworking industries ${ }^{1-3,5,7)}$. Eating patterns in shiftworking populations show a redistribution of food intake across the shift period, an increase in snacking behaviour and a change in macronutrient intake ${ }^{1,2)}$. There is also evidence in occupational settings for the strategic and increased use of foods and drinks containing caffeine as countermeasures associated with fatigue ${ }^{10)}$. However, these changes in food-type and timing are substantially influenced by operational and environmental factors ${ }^{1,2,4,5,11,12)}$. Research into meal-timing in flight attendants while crewing is lacking.

In flight attendants, the physical and social consequences of working time include chronic jet-lag and disruption to the circadian system, resulting in high levels of sleep disruption, fatigue and gastrointestinal upset ${ }^{4,5,13)}$. For flight attendants, working time appears to be a key factor impacting sleep duration, limiting healthy eating behaviours, and increasing fatigue-related incidents ${ }^{4,5,11)}$. A qualitative interview study of 14 Scandinavian flight attendants highlighted a highly stressful, decontextualised, and disrupted eating pattern due to logistical working conditions and restrictive schedules ${ }^{11)}$. While this previous study broached eating behaviours in flight attendants, no study has yet to quantify the nature of temporal patterns of eating, caffeine consumption, and health outcomes amongst flight attendants. The current study was a preliminary investigation of flight attendant sleep duration, snack/ meal-timing and frequency of caffeine use while crewing. Participants reported on what, when, and why food was ingested while crewing, as well as gastrointestinal symptoms experienced within the last two weeks.

Participants completed an online survey using the SurveyMonkey ${ }^{\odot}$ platform, subsequently advertised through a Flight Attendants Facebook ${ }^{\mathcal{O}}$ page. Prior to completing the survey participants were presented with a participant information sheet which stated that by submitting their survey responses they understood and were consenting to participate in the research. Ethics approval was granted by the Human Research Ethics Committee and the University of South Australia (No. 0000034874). Respondents completed the Survey of Shiftworkers (SOS), an abridged version of the Standard Shiftworker Index (SSI) ${ }^{14)}$ both valid and widely used tools exploring complex shift-schedules, worker health and well-being, which includes questions about sleep and gastrointestinal symptoms (http://www. workingtime.org/technical). Respondents also provided data for home city, current city for duty-period, sign-on time at port of departure (for current duty-period), and arrival port. Domicile time was assessed via reported home city and was used as the closest estimate of biological time.

Eating patterns while crewing was measured through a retrospective reporting system, requiring food intake frequencies to be reported during the respondent's last duty period. This part of the questionnaire was specifically designed for this group. Study aims were focused on food timing, and since recording of timing of food consumption is particularly complex for flight attendants, who are crossing time zones, the meal, snack, and caffeine recording questions were developed to be as simple and quick to complete as possible, and to be anchored to time into duty (which avoids the complexity of clock time). Since participants also reported domicile place and time, and departure port place and time, this allowed researchers to estimate food timing relative to biological time. The survey was finalised after piloting and consultation with cabin crew. A tabulated series of drop-down boxes was provided, requesting snack and meal frequencies and caffeinated drink or food frequencies for every hour on shift. Respondents could report as many meals, snacks or caffeinated goods frequencies consumed within that hour or conversely leave the hour blank if no food was ingested. Food timing and frequencies were reported for up to $20 \mathrm{~h}$ on shift. Instructions were: "For the duty period described above, please use the table below to mark for each hour while crewing if you ate a snack (e.g. fruit, cake, packet of chips) or meal (full dinner or lunch type meal) and/or if you consumed any caffeinated foods and/or drinks (coffee, chocolate, cola). If you did not eat or drink for that hour period please leave blank". Participants were provided with two open-ended questions (one for meals, one for snacks) and were asked to give examples of what they ate while crewing. Participants were also asked "Is this your typical eating pattern while crewing?"

Food cues were measured via three question sets asking, "what determines why/when/what you eat while crewing?" Responders could endorse up to fifteen multipleresponse cues adapted from ${ }^{12)}$. Cues included: Appetite, Habit, Social Interaction, Boredom, Cravings, Comfort, Cultural, Health Reasons, Taste Preferences, Scheduled Work Break, Level of Alertness, Time Available, Food Available, Don't Know, and Other.

In this cross-sectional study, a total of 34 respondents completed the survey. Of these, 13 participants were excluded (four participants had missing responses for variables of interest, eight were not in active duty, and one resided in Los Angeles rather than Australia), resulting in a sample of $n=21$ (mean age $=41.8, \mathrm{SD}=12.0 \mathrm{yr}$, 4 males, 17 females) for analyses. Average BMI was 23.8 


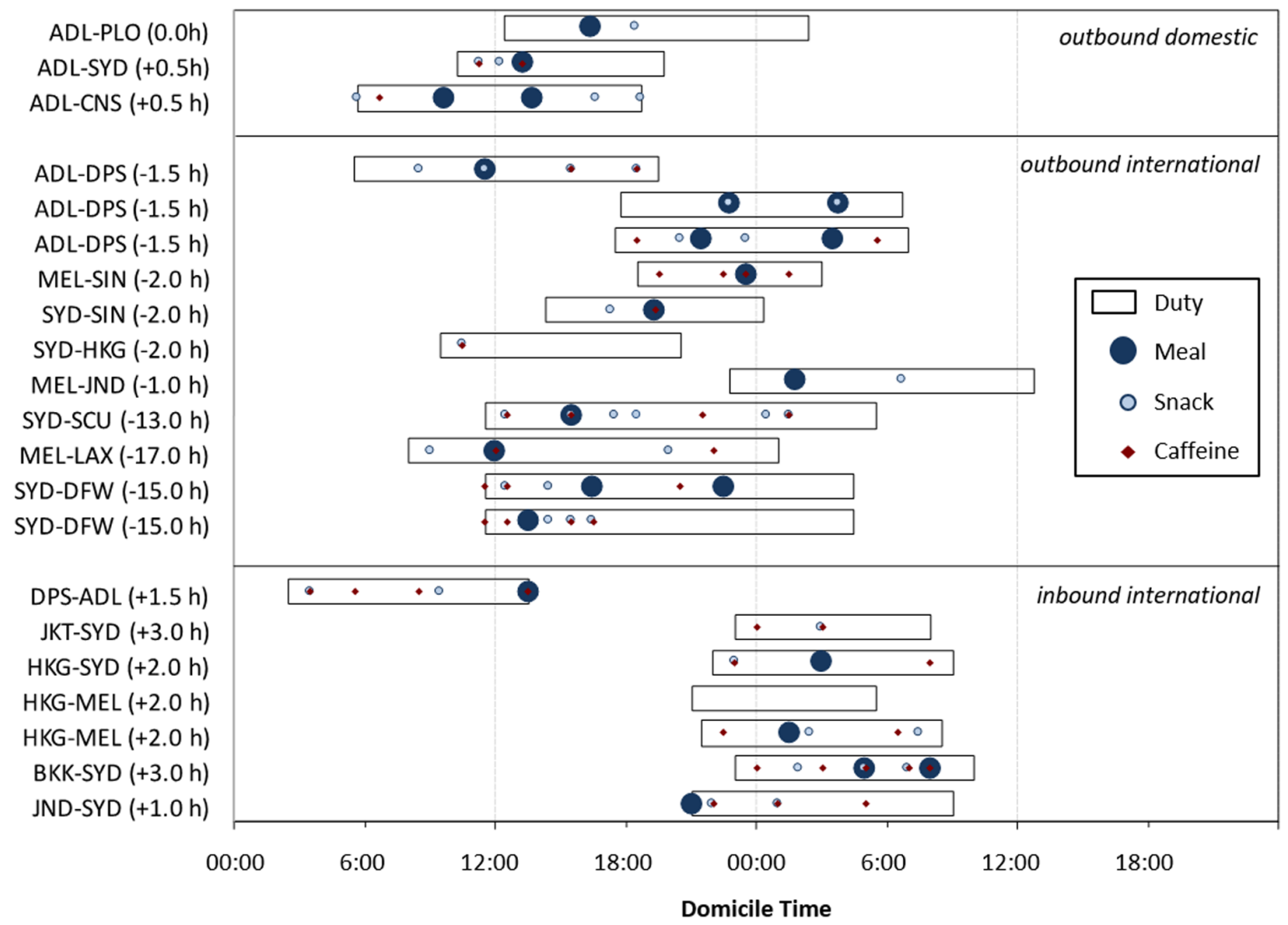

\begin{tabular}{|cccccccccc|}
\hline & \multicolumn{3}{c}{ duty length (h) } & \multicolumn{2}{c|}{ meals } & \multicolumn{2}{c|}{ O snacks } & \multicolumn{2}{c|}{ caffeine } \\
& $n$ & mean & $(\mathrm{SD})$ & mean & $(\mathrm{SD})$ & mean & $(\mathrm{SD})$ & mean & $(\mathrm{SD})$ \\
\hline outbound domestic & 3 & 12.2 & $(2.4)$ & 1.3 & $(0.6)$ & 2.0 & $(1.0)$ & 1.0 & $(1.0)$ \\
outbound international & 11 & 13.9 & $(3.2)$ & 1.3 & $(0.6)$ & 2.3 & $(1.7)$ & 2.1 & $(1.5)$ \\
inbound international & 7 & 10.5 & $(1.3)$ & 0.7 & $(0.8)$ & 1.9 & $(1.3)$ & 2.9 & $(1.2)$ \\
\hline overall 21 & 12.5 & $(2.9)$ & 1.1 & $(0.7)$ & 2.1 & $(1.5)$ & 2.2 & $(1.4)$ \\
\hline
\end{tabular}

Fig. 1. Reported duty times by International Air Transport Association (IATA) flight codes by domicile time, sorted by outbound/ inbound and domestic/international, with meals (large circles), snacks (small circles) and caffeine consumption (small diamonds) displayed across duty periods (n=21). ADL: Adelaide; PLO: Port Lincoln; SYD: Sydney; CNS: Cairns; DPS: Denpasar; MEL: Melbourne; SIN: Singapore; HKG: Hong Kong; JND: Japan; SCU: Santiago; LAX: Los Angeles; DFW: Dallas Fort Worth; JKT: Jakarta; BKK: Bangkok. Corresponding differences in time-zones for each flight are displayed in brackets after each flight (calculated during August-non-daylight savings time in South Australia, e.g. ADL-SYD involves landing in a time-zone that is $0.5 \mathrm{~h}$ ahead, or +0.5 h). Lower table indicates mean (SD: standard deviation) duty length, and number of meals, snacks, and occasions where caffeine was consumed for outbound domestic, outbound international, inbound international, and overall.

$(\mathrm{SD}=4.1) \mathrm{kg} / \mathrm{m}^{2}$. Respondents worked an average of 29.3 $(\mathrm{SD}=8.4)$ hours per week, with a work history of 13.0 $(\mathrm{SD}=10.4)$ yr. Reported sleep duration on workdays was $4.6 \mathrm{~h}(\mathrm{SD}=1.9 \mathrm{~h})$, which was significantly lower than sleep duration on days off $(\mathrm{M}=7.2 \mathrm{~h}, \mathrm{SD}=1.2 \mathrm{~h}$, paired samples $\left.t_{21}=6.6, p<0.001\right)$, and perceived sleep need $(\mathrm{M}=8.1 \mathrm{~h}$, $\mathrm{SD}=0.8 \mathrm{~h}$, paired samples $t_{21}=7.9, p<0.001$ ).

Reported duty periods are displayed in Fig. 1. There were three outbound domestic, twelve outbound interna- tional, and six inbound international flights. Average duty length was $12.5 \mathrm{~h}(\mathrm{SD}=2.9 \mathrm{~h})$. The time-zone difference between reported departure port and arrival port (calculated during non-daylight savings time in South Australia) is reported in Fig. 1. Meal and snack consumption was variable in amount and timing between crew and across duty periods. Five participants reported eating two meals on shift, 13 reported a single meal, two reported snacking only, and one reported not eating at all. Caffeine consumption was 


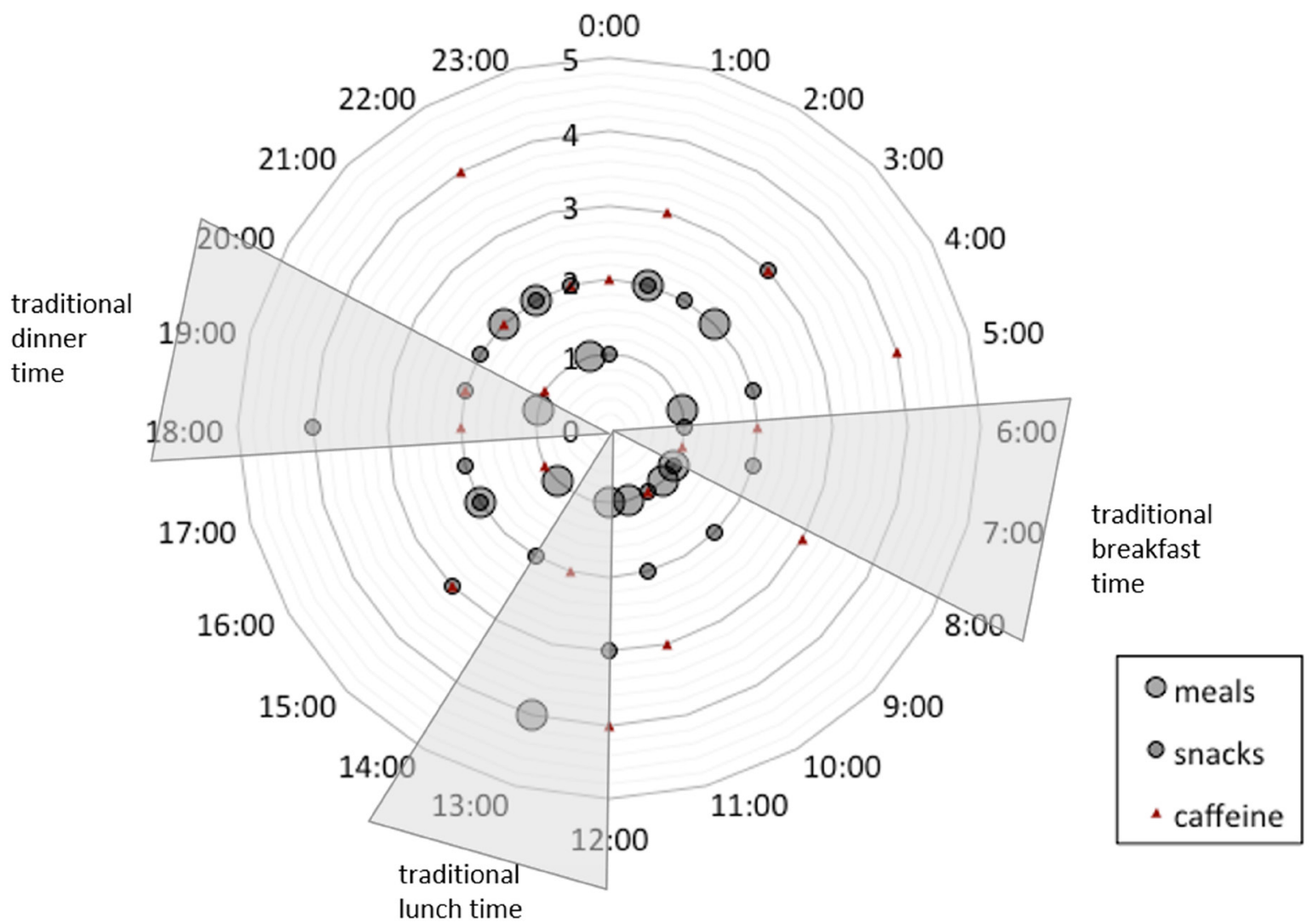

Fig. 2. Radar plot showing domicile time ( $24 \mathrm{~h}$ clock, circumference), the timing of meal/snack/caffeine intake by frequency (spoke axis, 1-5) with meals displayed (large markers), snacks displayed (small markers), and caffeine (red triangles) ( $n=21)$. Super-imposed are traditional breakfast, lunch and dinner timing during a standard sleep/wake cycle. The figure shows that meals, snacks, and caffeine were consumed around the clock, in and outside of traditional meal times, including throughout the night time hours. For example, while there were four instances of meals occurring at approximately 13:00 h (i.e. traditional lunchtime), there was only one meal recorded during the traditional dinner time window.

Respondents also gave qualitative responses describing meal and snack content. Meals included curry, pasta, salad, soup, noodles, rice, fish, stir-fry, sandwiches, steak, and vegetables. Snacks included chocolate, fruit, potato crisps, cookies, nuts, pretzels, cheese, and crackers.

reported by 17 (81\%) of participants, with consumption of up to 5 caffeinated goods in a duty period. Caffeine was consumed along with meals or snacks, as well as by itself. Figure 2 displays distribution of meals, snacks, and caffeine by domicile time, illustrating distribution around the clock (through day and night), outside of traditional meal times. Of the 21 respondents, $62 \%(n=13)$ indicated that this was typical food intake for them while crewing, $28 \%$ $(n=6)$ reported that they usually ate less, and $10 \%(n=2)$ reported that they usually ate more. Time available (endorsed for why $=76 \%$, what $=52 \%$, when $=86 \%$ of participants), food available ( $w h y=38 \%$, what $=81 \%$, when $=14 \%$ ), and work breaks ( why $=47 \%$, what $=23 \%$, when $=52 \%$ ), were the most endorsed reasons for food consumption on duty (Fig. 3, Upper Panel). Summarised responses to 'other' when asked why/what/when determines food eaten while crewing flight attendants reported: 'length of flight', 'nowhere to store food', 'aircraft temperature', 'eating before the flight', and 'don't eat on night sectors'. At least half of the respondents reported that they quite often or almost always experienced bloating or flatulence (62\%), disturbed appetite (62\%), and approximately $40 \%$ reported that they quite often or almost always experienced constipation or diarrhoea (Fig. 3, Lower Panel).

Consistent with previous research in other shiftworking groups ${ }^{1,2)}$, results suggest that flight attendants report reduced sleep associated with their work schedules. Sleep loss has been found to impact food selection, increasing preferences for high carbohydrate foods, negatively impacting metabolic health ${ }^{8,9}$. Further studies investigating food choice in more detail in flight attendants is therefore warranted. This study highlights the importance of study- 

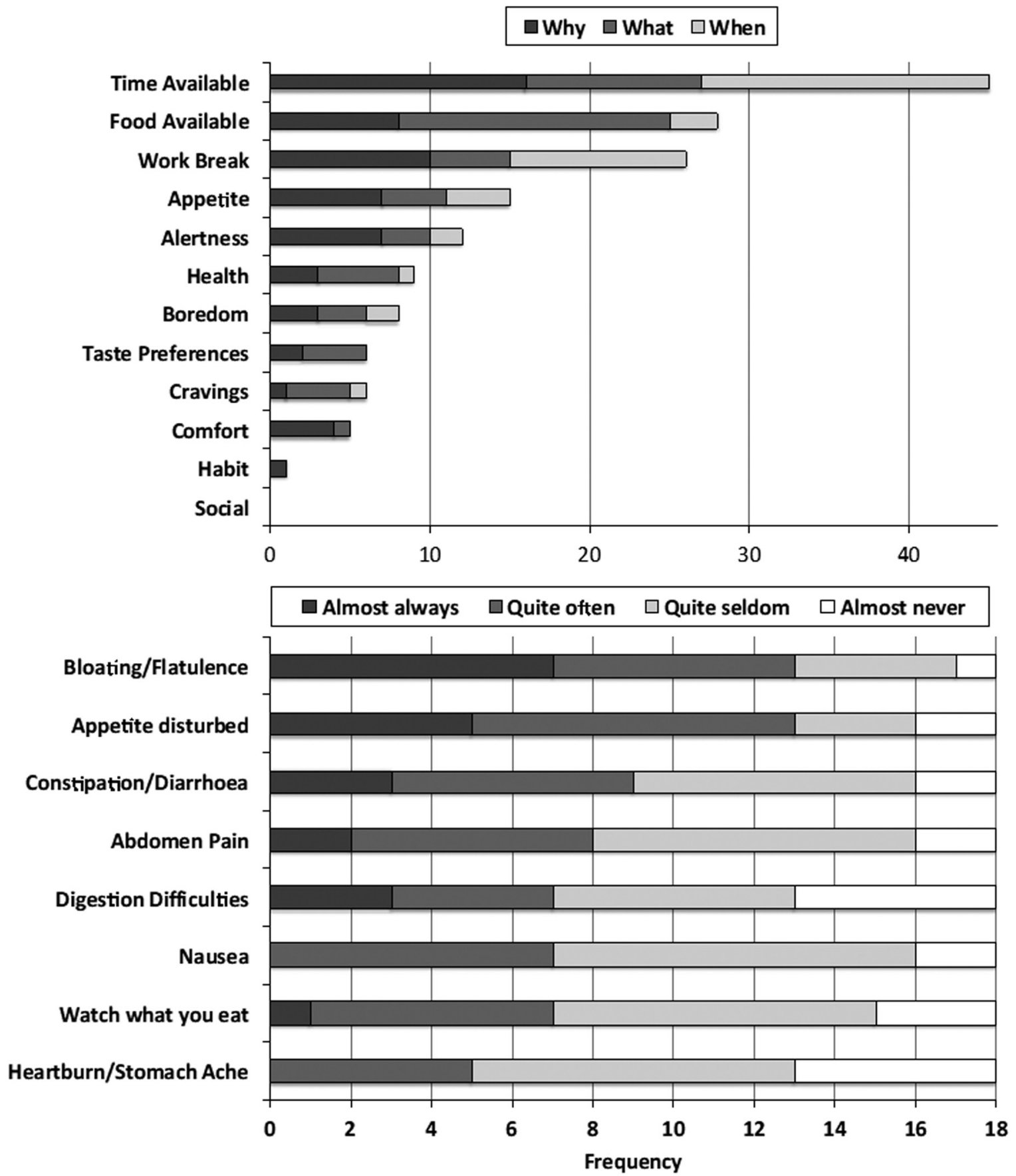

Fig. 3. Upper Panel: Stacked frequencies of endorsed food cues when asked when, what and why food was eaten during duty period, ranked from most to least endorsed; Lower Panel: Stacked frequencies of symptoms of gastrointestinal disturbance from most often, to least often experienced.

ing flight attendants' sleep and eating patterns, as well as overall health symptoms. Indeed, findings of the current study show snack and meal times that vary around the clock and across shifts. This is important because food is being eaten during a biologically incongruent time when we experience low levels of appetite, decreased gut motil- ity and decreased absorption and digestion rates ${ }^{2,3,7)}$.

Further, eating out of synchronisation with the circadian system can contribute to circadian disruption of peripheral organs responsible for metabolic health ${ }^{2,3,6,7)}$. Interestingly, these results are consistent with the findings of Nyberg and Lennernäs Wiklund ${ }^{11)}$, rather than appetite 
or habit motivating food consumption in this sample, the primary drivers for eating or not eating on duty appear to be work-driven - time and food available. In this previous qualitative study, Nyberg and Lennernäs Wiklund ${ }^{11)}$, identified food consumption as a 'preventative eating' strategy, consuming food prior to or during duty when time/food is available, a finding also reported in our study. Indeed, the distribution of food timing around the clock, despite relative consistency in domicile time (all respondents analysed were Australian) suggests that these work factors may be more powerful drivers of food consumption for cabin crew than biological drivers, such as the circadian rhythm in hunger.

Research suggests that eating during the night may have negative consequences for health, including gastrointestinal (GI) disturbance ${ }^{1,2,8,9,13)}$. The relatively high rates of GI symptoms reported by respondents in this study are consistent with this prior work. In addition, consistent with other shift working samples ${ }^{1,2,10)}$, caffeine use was frequent in this sample. While an effective short-term performance and alertness countermeasure, caffeine use, particularly in larger amounts, has been associated with GI disturbance ${ }^{10,13)}$ and reduced quality of subsequent sleep periods, which could be a concern in this sample-further disrupting circadian systems. Further, food consumption, particularly larger meals consumed during the biological night, has been shown to be associated with impaired glucose response to the following meals ${ }^{7-9}$. Research also suggests that large meals during the night may be associated with performance impairment over and above that seen typically seen across the night ${ }^{15)}$. Taken together, further research into eating patterns and associated work performance in flight attendants are necessary for both health and safety. Future research would benefit from collecting data on eating patterns during days off as well as work days. In particular, studies that include layovers would capture eating behaviours that are motivated by other occupational factors such as the time in the new environment and access to food items. Cultural differences in eating patterns would also be useful to examine. This survey was provided in English only, which necessarily limited the potential participant pool, and our small sample size is also a limitation of this preliminary study.

Working time in our sample of Australian flight attendants perturbs natural sleep-wake cycles, shortening sleep duration, and altering daily eating patterns. During shifts, eating behaviour is restricted by occupational factors, influencing food selection and timing. Further caffeine use is frequent, although the role it plays as either a countermea- sure for fatigue or if there are unintended effects on subsequent sleep and the circadian system is yet to be seen. The role eating patterns have on the circadian system is not yet clear, with eating patterns quantified during working time only. What is clear is that dietary and nutritional countermeasures for improved health should consider the working environment, as both individual and occupational factors are likely to be important.

\section{References}

1) Nea FM, Kearney J, Livingstone MBE, Pourshahidi LK, Corish CA (2015) Dietary and lifestyle habits and the associated health risks in shift workers. Nutr Res Rev 28, 143-66. [Medline] [CrossRef]

2) Lowden A, Moreno C, Holmbäck U, Lennernäs M, Tucker P (2010) Eating and shift work-effects on habits, metabolism and performance. Scand J Work Environ Health 36, 150-62. [Medline] [CrossRef]

3) Baron KG, Reid KJ (2014) Circadian misalignment and health. Int Rev Psychiatry 26, 139-54. [Medline] [CrossRef]

4) Avers KB, King JS, Thomas S, Banks J (2009) Flight Attendant fatigue, part I: National duty, rest, and fatigue survey. (DOT/FAA/AM-09/24). Office of Aerospace Medicine, Washington DC.

5) Roma PG, Mallis MM, Hursh SR, Mead AM, Nesthus TE (2010) Flight attendant fatigue recommendation ii: flight attendant work/rest patterns, alertness, and performance assessment (DOT/FAA/AM-10/22). Office of Aerospace Medicine, Washington DC.

6) Morris CJ, Yang JN, Garcia JI, Myers S, Bozzi I, Wang W, Buxton OM, Shea SA, Scheer FAJL (2015) Endogenous circadian system and circadian misalignment impact glucose tolerance via separate mechanisms in humans. Proc Natl Acad Sci USA 112, E2225-34. [Medline] [CrossRef]

7) Zarrinpar A, Chaix A, Panda S (2016) Daily eating patterns and their impact on health and disease. Trends Endocrinol Metab 27, 69-83. [Medline] [CrossRef]

8) Grant CL, Coates AM, Dorrian J, Kennaway DJ, Wittert GA, Heilbronn LK, Pajcin M, Della Vedova C, Gupta CC, Banks S (2017) Timing of food intake during simulated night shift impacts glucose metabolism: A controlled study. Chronobiol Int 34, 1003-13. [Medline] [CrossRef]

9) Centofanti S, Dorrian J, Hilditch C, Grant C, Coates A, Banks S (2017) Eating on nightshift: a big vs small snack impairs glucose response to breakfast. Neurobio Sleep Circadian Rhythms, 4.

10) McLellan TM, Caldwell JA, Lieberman HR (2016) A review of caffeine's effects on cognitive, physical and occupational performance. Neurosci Biobehav Rev 71, 294-312. [Medline] [CrossRef]

11) Nyberg M, Lennernäs Wiklund M (2017) Impossible meals? The food and meal situation of flight attendants in 
Scandinavia - a qualitative interview study. Appetite 113, 162-71. [Medline] [CrossRef]

12) Waterhouse J, Buckley P, Edwards B, Reilly T (2003) Measurement of, and some reasons for, differences in eating habits between night and day workers. Chronobiol Int 20, 1075-92. [Medline] [CrossRef]

13) Enck P, Müller-Sacks E, Holtmann G, Wegmann H (1995) Gastrointestinal problems in airline crew members. Z Gastroenterol 33, 513-6. [Medline]

14) Barton J, Spelten E, Totterdell P, Smith L, Folkard S,
Costa G (1995) The Standard Shiftwork Index: a battery of questionnaires for assessing shiftwork-related problems. Work Stress 9, 4-30. [CrossRef]

15) Gupta CC, Dorrian J, Grant CL, Pajcin M, Coates AM, Kennaway DJ, Wittert GA, Heilbronn LK, Della Vedova CB, Banks S (2017) It's not just what you eat but when: the impact of eating a meal during simulated shift work on driving performance. Chronobiol Int 34, 66-77. [Medline] [CrossRef] 